\title{
Research on Progress Control of Overseas Cement EPC General Contracting Project
}

\author{
Jianke Gu* \\ Suzhou Sinoma Construction Co., Ltd., Suzhou 215300, Jiangsu Province, China \\ *Corresponding author: Jianke Gu, chenfu0425@163.com
}

\begin{abstract}
The purpose of Engineering Procurement Construction (EPC) general contracting project schedule management is to ensure that the project meets its deadlines, and it plays a critical role in contract performance. In comparison to the domestic general contracting model, project management and coordination are more complex for the general contractor of international EPC projects. As a result, scientific project schedule process control is critical to effectively ensuring project duration, saving project costs, improving project management level, and project quality, and ensuring that the project achieves the promised advantages for both the contractor and the owner. Through the research and analysis of the status of the schedule management of the Indonesia B Project Phase II cement project, corresponding optimization measures are proposed for the project schedule process control.
\end{abstract}

Keywords: EPC cement engineering; Project management; Schedule management; Process control

Publication date: November 2021; Online publication: November 30, 2021

\section{Introduction}

At present, the "Going Abroad" and "One Belt One Road" initiative of China has reached broad consensus in various industries and regions around the world, and has achieved fruitful achievements. The cement engineering industry is one of the earliest industries in China that to go abroad. As the domestic cement engineering contracting market gradually becomes saturated, more and more cement engineering companies are looking at overseas markets, which increases competition in overseas cement engineering projects. To gain a foothold in the fierce competition, cement engineering contracting companies must strengthen the study and research of overseas engineering project management theory, make full use of the knowledge of project planning, schedule management, resource management, etc., and accumulate project management experience through practice ${ }^{[1]}$.

This article takes the Indonesia B Project Phase II cement project EPC project ${ }^{[2]}$ as a case, and uses scientific and advanced schedule management related theories and technologies to study the project schedule control process, find out the key factors affecting the project schedule and propose corresponding measures.

\section{Project overview}

The Indonesia B Project Phase II cement project is a 10,000t/d clinker cement production line. The project site is located in the LEBAK district, Banten, southwest of Java Island, Indonesia. The topography of the factory site is seaside hills, which is about $50 \mathrm{hm}^{2}$ and could accommodate two 10,000t/d production lines. This project is the second $10,000 t / d$ production line. The contract period is 22 months. The raw materials and fuels of the project are different from conventional standards. The raw materials have high moisture content and are prone to blockage, which requires high quality equipment. The local dry season is from 
April to November each year, and the rainy season is from November to March of the following year. The project construction period lasts 3 rainy seasons.

\section{Difficulties in project schedule management}

The Indonesia B Project Phase II cement project is a large-scale project with a huge amount of work. The the main structure concrete is more than 70,000 cubic meters, the steel structure is more than 6,000 tons, the slope protection is more than 160,000 square meters, the weight of process equipment is more than 12,000 tons, and the length of cable exceeds 600 kilometers. The construction period is very tight. The final effective construction period of this project is less than 18 months due to the owner's twice advance requirements for the construction period. The delivery period of main equipment of the project is long, some process equipment is difficult to install, construction operations are crossed, and the coordination workload is large and difficult, which request the high organization and coordination ability of the project schedule management team. In addition, there are also difficulties in the project as follow:

(1) Overseas engineering projects generally belong to the "three-ing" projects, which means designing, bidding, and constructing carry out simultaneously, which is inefficient and slow in progress ${ }^{[3]}$.

(2) Due to the special production raw materials, the use of the limestone round stacker and reclaimer equipment in Indonesia B Project Phase I cement project is not as good as expected, and higher costs were spent on transformation in the mid-term, which resulting in partial cost overruns of the project. Therefore, the equipment supplier of Indonesia B Project Phase II cement project is replaced by European manufacturers, and the delivery time of equipment is quite long.

(3) In order to avoid taxes reasonably, the owner requires all equipment and materials imported from China for this project must take the exemption procedures. However, the owner did not fully understand the customs' new requirements for exemption list and were often returned and revised by the local customs authorities repeatedly, which affected the progress of logistics shipments.

(4) The plans for the main links of design, procurement, logistics, and on-site construction did not form an effective combination. The overall project schedule is not good enough.

(5) There were a lot of new technologies, new materials, and new equipment taken in Indonesia B Project Phase II cement project during the implementation. Many construction workers are also exposed to such new technologies and new technologies for the first time, and it is difficult to grasp the technical points for a while.

In addition, due to local government certificate restrictions and project cost reduction and efficiency requirements, the Phase II of the project has a higher degree of localization engineering than the Phase I. By reason of the technical level of the local workers, the construction efficiency inevitably decreased, which brought great challenges to the implementation of the project schedule as planned.

\section{Strengthening measures for project schedule process control}

\subsection{Strengthen the progress control of the design and procurement process}

From the perspective of the entire implementation process of the EPC project, the design work and procurement work are at the beginning and intermediate stage of the project, which are also the key links that restricts whether the project could be performed on schedule. Design, procurement, and construction works like chains that one leads to another. Delays in design drawings, delays in equipment delivery, quality problems in design drawings, and equipment quality problems will inevitably cause the effective construction period to be shortened. It results in a situation that the schedule is loose at the beginning of the project, as well it is tight at the end, which increases additional risks during the construction phase ${ }^{[4]}$.

(1) Design: pay attention to the information exchanging among departments such as processing, structure, architecture, electrical, HVAC, etc., especially pay attention to the information providing 
of processing, and also pay special attention to the input of external design conditions.

(2) Purchasing: the information and data proving of the manufacturer is the key to affecting the design progress, especially the information of the host equipment data needs to be paid serious attention to. Equipment manufacturing and logistics delivery are the keys to the construction schedule. Equipment that affects the on-site construction schedule should be planned and prepared in advance.

(3) Interface management between design and procurement: in order to avoid delays due to communication failures, in the early period of the EPC project, it is necessary to pay special attention to the communication of the design and procurement interface, the flow chart of interface between design and procurement is shown in Figure 1. In order to achieve the best management effect, it is necessary to formulate a special management process to minimize the cost of information communication between design, procurement and equipment suppliers; and to simplify the management interface between design and procurement from the organizational structure, and finally achieve seamless connection. The interface between design and procurement of Indonesia B Project Phase II cement project is as follow.

To supervise and urge the provision of equipment information and prices;

To supervise the design confirmation progress

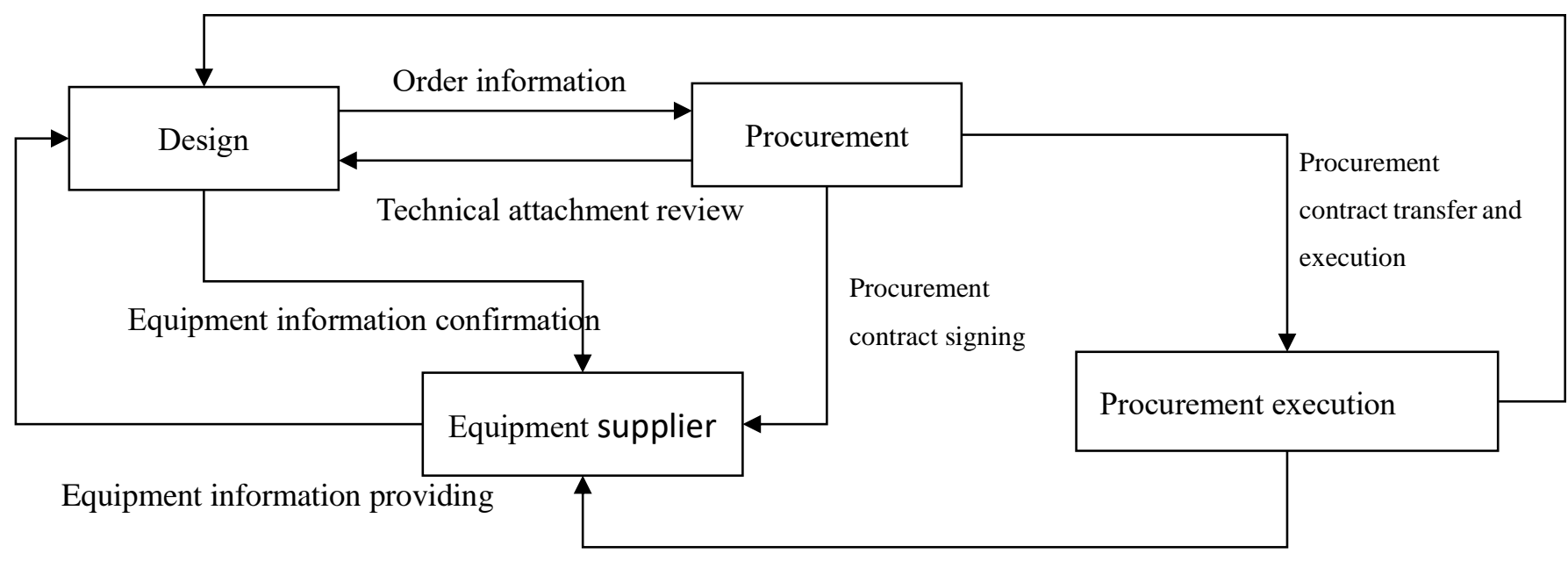

Expediting and manufacturing supervision

Figure 1. The flow chart of interface between design and procurement

\subsection{Strengthen the management of construction subcontractors}

\subsubsection{Strengthen subcontractor contract management measures}

A subcontract is a responsibility and scope agreement between the general contractor and the construction subcontractor. It is a basic way to use market mechanisms to achieve the purpose of performance. The subcontracting contract stipulates the scope of project, quantity, quality requirements, construction period requirements, special construction technical requirements of the subcontractor, and also payment methods for the project. The overall goal of the project could be detailed and decomposed into each stage node goal. Taking the Indonesia B Project Phase II cement project as an example, there are cross-installation nodes of the furnace end frame foundation, nodes of frame capping, etc., and pay part of the progress payment as a node reward. On one hand, the payment schedule of the project progress payment is more accurate and clearer. On the other hand, it can effectively improve the enthusiasm of the construction subcontractor, actively optimize the organization plan, and increase the personnel and machinery to promote the project progress. 


\subsubsection{Strengthen the organization and management of subcontractors}

During on-site construction, the subcontractor is the specific implementer of the project schedule. The smooth progress of the project schedule depends on the overall coordination and management of the general contractor on the one hand, and must also be actively cooperated by the subcontractor. The quality and ability of the personnel assigned by the construction subcontractor is very important. The main purpose is to achieve the goal of effectively controlling the construction progress by strengthening active control to synchronize the actual progress with the planned progress.

\subsubsection{Introduce incentive measures that combine rewards and punishments}

Economic stimulus has always been an effective means to promote the development of things for the better, and it is also effective when applied to the progress control of engineering projects. For a long time, the general contractor has imposed punishment on the subcontractor's time limit always, but from the perspective of actual implementation, the effect has not been great. Regardless of the owner or the general contractor, the purpose of project execution is to perform the contract on time rather than to punish. Under the conditions of rewards, subcontractors will more actively cooperate with the progress management of the general contractor to promote the realization of project progress goals.

\subsection{Balance the tripartite relationship of quality, cost and schedule}

In the process of project implementation, schedule, cost, quality, and safety are the four main elements of project management, of which safety is the unconditional first element. The three elements of quality, cost, and schedule restrict and promote each other. How to balance the impact of quality and cost on the schedule is an important topic for the smooth progress of the project schedule. If blindly sacrificing cost and quality for the sake of project progress is not advisable, it may lead to serious consequences. Reasonably focusing on a certain factor at different stages may be more in line with the actual situation of the project. For the Indonesia B Project Phase II cement project, strengthening quality management under controllable costs is undoubtedly an important means to ensure the progress of the project and reduce unnecessary waste of investment.

In terms of quality, laws and regulations on quality management should be strictly implemented. To establish a quality management organization system for the project department, to clear goals and unify coordination. To implement the quality management responsibility system, clarify the quality management responsibilities of the various departments of the project department and their managers and operators. To establish a quality management education and training system to improve the quality of personnel management. To organize relevant personnel to compile construction organization design or special construction plan, and clarify the key points of quality control and corresponding measures. To organize all professional management personnel to conduct review of drawings to eliminate hidden quality hazards and rework from the source. To complete the technical clarification, work according to the approved construction plan and other documents. To ensure that all the site operators understand the quality requirements very clearly. To complete self-inspection, mutual inspection, handover inspection and special inspection successfully, and strengthen the acceptance of concealed engineering. The main equipment should be installed with a dedicated person to check the whole process to ensure that there is no mistake in the installation. To carry out monthly quality inspection activities, with the participation of the project leaders, technical leaders and main quality management personnel of the general contractor and subcontractor, rewarding the good and punishing the bad, and strengthening the management and control of the project quality. To organize the technical experts or industry experts to give lectures and training on site regularly, to learn and master advanced technical management knowledge and innovative ideas, in order to promote the progress of project quality management. 
In terms of cost, it is necessary to make a cost control plan at the beginning of the project. To control costs by planning control measures in advance to ensure progress.

\subsection{Strengthen safety management to ensure progress management}

In the process of project construction, safety work always comes first. The safety issues often occur in the period of on-site construction and commissioning. Starting from the overall situation of ensuring the longterm healthy and stable development of the enterprise and protecting the life and safety of workers, it is necessary to increase investment in safety costs, improve infrastructure protection capabilities, increase employee training and education, and further enhance employees' awareness of safety and quality, so that employees can learn from a deeper level and recognize the relationship between safety, quality, progress and development and benefits, and firmly establish a sense of responsibility that safety, quality, and progress are closely related to operations. In the safety work, it is necessary to force the work permit, always focus on safety observation and communication and work safety analysis, reduce the unsafe state of things, put an end to unsafe behavior of people, build a safe construction environment, and ensure the normal construction progress. In terms of the safety management of subcontractors, the general construction contractor must effectively control the qualifications and personnel quality of the subcontractors, strictly control the safety system of the subcontractors, implement dynamic safety management, and strengthen supervision.

\section{Conclusion}

The purpose of EPC general contracting project progress control is to guarantee that the project meets its expected progress goal. This paper analyses and studies the progress control in the cement engineering general contracting project management by combining the case of the engineering general contracting project of Indonesia B Project Phase II cement project. A variety of realistic progress management improvement strategies were proposed, which were combined with the project's actual circumstances, to handle the problem of progress management in a targeted manner. The Indonesia B Project Phase II cement project's project schedule management level was eventually improved, and the project plan objectives were effectively controlled. The four key goals of progress, quality, cost, and safety were all met on time, and the progress targets were accomplished two and a half months ahead of schedule. The general contractor's execution efficiency and quality for an international project were also significantly enhanced.

\section{Disclosure statement}

The author declares no conflict of interest.

\section{References}

[1] Kirzner H, 2014, Project Management-A Systematic Approach to Plan Schedule and Control. Beijing: Publishing House of Electronics Industry, (06).

[2] Li J, 2014, EPC Cement Engineering Project Schedule Management Research and System Development. Concrete Engineering, 4(26): 3459-3460.

[3] Liu L, 2018, Analysis of Progress Management of Overseas Cement Plant Projects. Architectural Engineering Technology and Design, 24: 3073.

[4] Cao W, 2017, Analysis of Progress Control and Restrictive Factors of International EPC Engineering Projects. Project Management Technology, (12):46-50. 